Abstracta Iranica Abstracta Iranica

Revue bibliographique pour le domaine irano-aryen

Volume 34-35-36 | 2017

Comptes rendus des publications de 2011-2013

\title{
E. Basso. The Pottery of Southern Cappadocia: Preliminary Petrographic Analyses of Sherds from Northern Tyanitis
}

\section{Astrid Nunn}

\section{(2) OpenEdition \\ Journals}

Édition électronique

URL : http://journals.openedition.org/abstractairanica/41542

DOI : 10.4000/abstractairanica.41542

ISSN : 1961-960X

Éditeur :

CNRS (UMR 7528 Mondes iraniens et indiens), Éditions de l'IFRI

Référence électronique

Astrid Nunn, «E. Basso. The Pottery of Southern Cappadocia: Preliminary Petrographic Analyses of Sherds from Northern Tyanitis », Abstracta Iranica [En ligne], Volume 34-35-36 | 2017, document 20, mis en ligne le 15 juillet 2016, consulté le 29 septembre 2020. URL : http://journals.openedition.org/ abstractairanica/41542 ; DOI : https://doi.org/10.4000/abstractairanica.41542

Ce document a été généré automatiquement le 29 septembre 2020.

Tous droits réservés 


\title{
E. Basso. The Pottery of Southern Cappadocia: Preliminary Petrographic Analyses of Sherds from Northern Tyanitis
}

\author{
Astrid Nunn
}

\section{RÉFÉRENCE}

E. Basso. « The Pottery of Southern Cappadocia: Preliminary Petrographic Analyses of Sherds from Northern Tyanitis ", in : L. d'Alfonso, M.E. Balza, C. Mora, eds., GeoArchaeological activities in Southern Cappadocia - Turkey. Italian University Press, 2010, p. 71-80. (Studia Mediterranea, 22)

1 La province classique de la Tyanitis correspond à l'actuelle région de Niğde. L'Université de Pavie y a fait une prospection sur environ 30 sites et rassemblé 1000 tessons diagnostiques de céramique. Ils couvrent une période qui va du néolithique au Moyen Âge. L'époque achéménide est incluse dans le Late Iron Age (VII ${ }^{\mathrm{e}} 350 \mathrm{av.} \mathrm{J.-C.)}$ et est représentée par environ 40 tessons.

\section{AUTEURS}

\section{ASTRID NUNN}

Université de Munich 